\title{
The biomechanical strength of olecranon fixation constructs: a systematic review and meta-regression
}

\author{
Brenden Cutter*, Shayne R. Kelly, Charles R. Beckett, Eric G. Huish
}

Valley Consortium for Medical Education, Modesto, California, USA

Received: 06 October 2021

Revised: 25 November 2021

Accepted: 06 January 2022

\section{*Correspondence: \\ Dr. Brenden Cutter, \\ E-mail: Bcutter16@gmail.com}

Copyright: (c) the author(s), publisher and licensee Medip Academy. This is an open-access article distributed under the terms of the Creative Commons Attribution Non-Commercial License, which permits unrestricted non-commercial use, distribution, and reproduction in any medium, provided the original work is properly cited.

\begin{abstract}
Olecranon fractures are often operative when displaced over $2 \mathrm{~mm}$, but the most stable fixation construct is debated. The purpose of this study was to provide an overview of biomechanical properties of the most commonly used surgical fixations of olecranon fractures. This systematic review included 13 biomechanical studies comparing displacement during cyclic loading of olecranon fractures fixated with either tension band wiring (TBW), intramedullary screw, or plate fixation. In regard to overall gapping, plates displayed (and screws trended towards) increased stability versus TBW. However, there was no difference between the constructs in gapping at the articular surface. Plating displayed increased stability along the posterior surface. No construct allowed gapping over $2 \mathrm{~mm}$, suggesting safe early postoperative motion with any of the techniques.
\end{abstract}

Keywords: Olecranon fracture, Olecranon fixation, Biomechanical, Cadaveric

\section{INTRODUCTION}

Olecranon fractures are among the most common injuries of the upper extremity. ${ }^{1}$ Most surgeons elect for operative intervention when displaced over $2 \mathrm{~mm} .^{2}$ Goals of fixation include anatomic reduction of the articular surface, restoration of active elbow extension, and prevention of elbow stiffness.

Tension band wiring (TBW) is regarded as the gold standard for fixation of simple transverse olecranon fractures. ${ }^{1,4}$ Originally described by Weber and Vasey using intramedullary Kirschner wires (K-wires), this technique converts eccentric forces of the triceps into compressive forces at the articular surface. ${ }^{3}$ Complications related to $\mathrm{K}$-wire skin irritation, skin penetration, and infection have led many to explore other modes of fixation..$^{5}$ A popular modification includes fixation of the $\mathrm{K}$-wires through the anterior cortex in an effort to increase stability and decrease posterior migration. ${ }^{5}$ Other techniques include plating, intramedullary (IM) screws, wires or sutures alone, olecranon sleds, and intramedullary nails. ${ }^{1,5-9}$ There has been a recent shift in the management of these fractures towards the use of precontoured locking plates; however, this comes with increased implant cost.

Despite generally good results, complications including loss of fixation, nonunion, and need for revision surgery do occur. ${ }^{1,11}$ Even planned olecranon osteotomies suffer from problems of nonunion and loss of fixation. ${ }^{12}$ These patients are also prone to elbow stiffness, especially if immobilization is prolonged. ${ }^{13}$

With a new emphasis on early active range of motion, the optimal construct is able to maintain fracture control during physiologic loading. Recent biomechanical studies comparing these fixation techniques have focused on displacement at the fracture site in response to cyclic 
loading that simulates high-intensity physiologic demands. ${ }^{7,8,14-25}$ To better understand the biomechanical properties of olecranon fixation constructs, we performed a systematic review and meta-regression of published data related to this topic.

\section{METHODS}

\section{Article screening}

We searched the PubMed database on 19 April, 2021 for articles evaluating the biomechanical characteristics of olecranon fixation with displacement at the fracture site as a primary outcome. The search field entered was: "Olecranon"[all fields] AND ("Osteotomy"[all fields] OR "Fracture"[all fields]) AND ("Biomechanical"[all fields] OR "Biomechanic"[all fields] OR "Biomechanics"[all fields]). Two authors (SK, BC) independently screened the resulting 138 articles for inclusion or exclusion using the Abstrackr software (Brown, Providence, RI). ${ }^{26}$ Inclusion criteria were biomechanical studies of olecranon fixation performed on human cadavers that reported displacement at the fracture site during cyclic loading through the extensor mechanism. As TBW and intramedullary screws rely on compression at the fracture site, we only included studies that evaluated simple fracture patterns with good cortical contact. We excluded studies that were in another language, failed to report displacement with standard deviation or sample size, and solely evaluated comminuted fractures.

After performing a full text review of the articles selected by the two reviewers, 13 studies met inclusion and exclusion criteria (Figure 1). These studies represent biomechanical data examining three types of olecranon constructs: traditional K-wire tension band wiring, a single intramedullary screw, and plate fixation. Studies evaluating constructs that fell outside of these categories were excluded. There were four studies evaluating the stability of intramedullary locking nails, but these failed to report standard deviation data and therefore could not be included..$^{8,27-29}$ The reference sections of the included articles were screened for additional studies, but none met inclusion criteria. These articles were then evaluated for quality using the Quality Appraisal for Cadaveric Studies scale. ${ }^{30}$

\section{Data collection}

Data collected from each study included study size, implants used, average age of the cadavers, and location of displacement measured. To better explore if certain fixation characteristics had an affect on the biomechanical properties, additional information was recorded for each construct type, such as K-wire position (intramedullary versus transcortical) in TBW, screw size, and type of plating used.

\section{Included studies}

The 13 included studies represent 274 cadaveric specimens and 55 cohorts of olecranon fractures fixated with either tension band wiring, intramedullary screw, or plating technique (Table 1). ${ }^{7,8,14-25}$ Cohorts that tested fracture patterns with no cortical contact were eliminated. These studies evaluated maximum mean displacement at the fracture site during cyclic loading of the extensor mechanism. Selected studies simulated high-load physiologic daily activities such as pushing out of a chair or performing a push-up. Many of the studies measured displacement at either one or both of the following locations on the olecranon: anterior articular surface (within $5 \mathrm{~mm}$ of the articular surface), or posterior olecranon surface (within $5 \mathrm{~mm}$ of the dorsal surface).

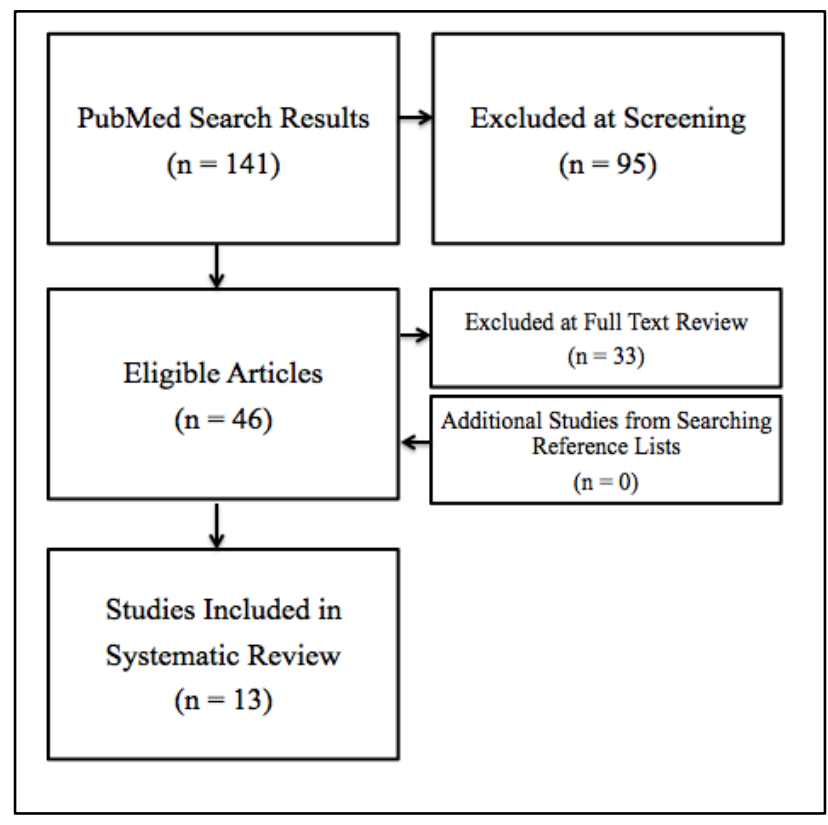

Figure 1: Study selection.

\section{Statistical analysis}

A random effects meta-regression was performed using OpenMeta [Analyst] (Brown, Providence, RI) comparing pooled displacement values between groups utilizing TBW, IM screw, and plate fixation. Meta-regression was also performed comparing measurements on the articular side of the olecranon to those on the posterior cortical surface. Cohorts were then subdivided into those measuring displacement at these two locations, with comparisons between fixation groups again performed for each type of fixation. Within the TBW group, comparison was performed between those using intramedullary Kwires and those with transcortical K-wires. Finally, comparison based on cadaveric age was also performed. Statistical significance was set at $\mathrm{p}<0.05$. 


\section{RESULTS}

When comparing tension band wiring, intramedullary screw, and plating constructs in regard to average maximum displacement at the fracture site, the reported displacements were $0.696 \mathrm{~mm}(0.539-0.854), 0.374 \mathrm{~mm}$ (0.090-0.657), and $0.419 \mathrm{~mm}(0.201-0.637)$ respectively (Table 2). The difference between plate fixation and TBW was significant $(\mathrm{p}=0.043)$, while the difference between screw fixation and TBW approached significance $(\mathrm{p}=0.051)$. When examining the data based on the location of measured displacement, the posterior cortical surface displayed increased gapping versus the articular surface for all constructs $(0.786 \mathrm{~mm}(0.626-0.945)$ versus 0.389 $\mathrm{mm}(0.239-0.538), \mathrm{p}<0.001)$. As the age of the cadavers increased, the average gap actually decreased at both the articular surface $(-0.002 \mathrm{~mm} / \mathrm{year}(-0.016-0.012))$ and posterior cortex $(-0.017 \mathrm{~mm} /$ year $(-0.037-0.003))$, but neither of these findings were statistically significant ( $p=0.807, p=0.102$ respectively).

Table 1: Characteristics of included studies.

\begin{tabular}{|c|c|c|c|c|c|}
\hline Lead author & Year & Sample size & Cohorts & Fixation & QUACS scale \\
\hline Boden & 2018 & 32 & 4 & Plate & 11 \\
\hline Carofino & 2007 & 80 & 8 & TBW, Screw & 11 \\
\hline Gruszka & 2015 & 24 & 2 & TBW, Plate & 11 \\
\hline Gruszka & 2017 & 54 & 6 & TBW, Plate & 11 \\
\hline Hackl & 2017 & 42 & 6 & Plate & 11 \\
\hline Hammond & 2012 & 24 & 4 & TBW & 11 \\
\hline Hutchinson & 2003 & 40 & 8 & TBW, Screw & 11 \\
\hline Lalliss & 2010 & 19 & 3 & TBW & 11 \\
\hline Lalonde & 2005 & 12 & 2 & TBW & 9 \\
\hline Midtgaard & 2020 & 40 & 2 & TBW, Plate & 13 \\
\hline Petraco & 1996 & 36 & 3 & TBW, Screw & 11 \\
\hline Prayson & 1997 & 44 & 4 & TBW & 11 \\
\hline Sadri & 2011 & 24 & 3 & TBW & 11 \\
\hline
\end{tabular}

QUACS-quality appraisal for cadaveric studies.

Table 2: Average maximum displacement at fracture site during cyclic loading.

\begin{tabular}{|ll|}
\hline TBW & $0.696(0.539-0.854)$ \\
\hline Screw & $0.374(0.090-0.657) \mathrm{p}=0.051$ \\
\hline Plate & $0.419(0.201-0.637) \mathrm{p}=0.043^{*}$ \\
\hline
\end{tabular}

*Significant.

Table 3: Average maximum displacement measured at articular and posterior locations during cyclic loading.

\begin{tabular}{|lll|}
\hline & $\begin{array}{l}\text { Articular } \\
\text { Displacement } \\
(\mathbf{m m})\end{array}$ & $\begin{array}{l}\text { Posterior } \\
\text { Displacement }(\mathrm{mm})\end{array}$ \\
\hline TBW & $\begin{array}{l}0.469(0.314- \\
0.624)\end{array}$ & $0.961(0.744-1.179)$ \\
\hline Screw & $\begin{array}{l}0.218(-0.043- \\
0.480) \mathrm{p}=0.106\end{array}$ & $\begin{array}{l}0.690(0.170-1.210) \\
\mathrm{p}=0.345\end{array}$ \\
\hline Plate & $\begin{array}{l}0.246(-0.020- \\
0.512) \mathrm{p}=0.157\end{array}$ & $\begin{array}{l}0.532(0.252-0.812) \\
\mathrm{p}=0.018^{*}\end{array}$ \\
\hline
\end{tabular}

*Significant.

The tension band wiring constructs were associated with an average maximum gap of $0.469 \mathrm{~mm}(0.314-0.624)$ at the articular surface and $0.961 \mathrm{~mm}(0.744-1.179)$ at the posterior olecranon surface. When examining different Kwire techniques, the intramedullary $\mathrm{K}$-wire construct displayed gapping of $0.593 \mathrm{~mm}(0.187-0.998)$ and 1.142 $\mathrm{mm}(0.783-1.501)$ at the articular and posterior surfaces respectively. The transcortical K-wire TBW displayed articular gapping of $0.459 \mathrm{~mm}(0.230-0.687)$ and posterior gapping of $0.839 \mathrm{~mm}(0.520-1.158)$. There were no differences seen when comparing the two K-wire configurations at either the articular $(\mathrm{p}=0.573)$ or posterior surface $(\mathrm{p}=0.216)$.

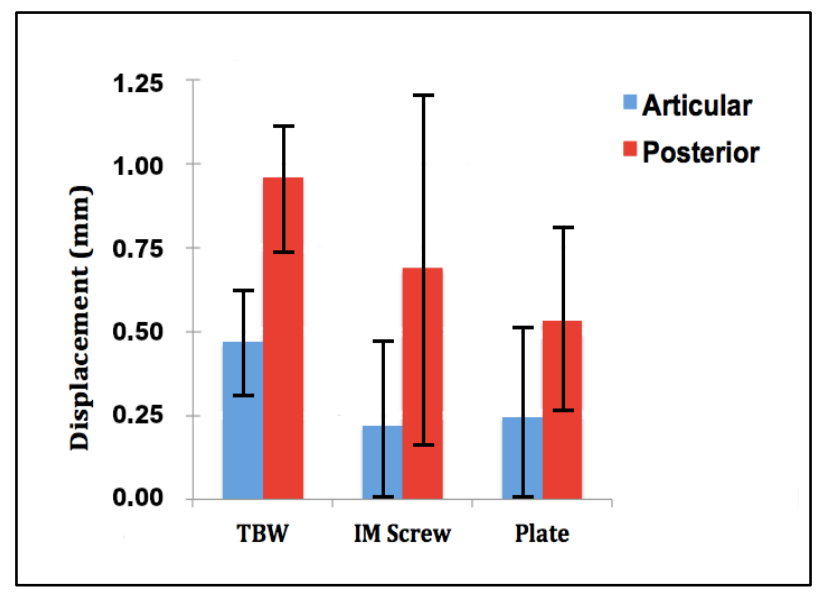

Figure 2: Average maximum displacement measured at articular and posterior locations during cyclic loading. 
Intramedullary screw constructs displayed average articular sided displacement of $0.218 \mathrm{~mm}(0.043-0.480)$ and posterior sided displacement of $0.690 \mathrm{~mm}(0.170-$ 1.210). When compared to TBW, screw techniques displayed no difference in fracture stability at either the articular $(\mathrm{p}=0.106)$ or posterior surface $(\mathrm{p}=0.345)$. Plating displayed an average articular gap of $0.246 \mathrm{~mm}(-0.020-$ $0.512)$, which was not significantly different from TBW $(p=0.157)$. However, when evaluating the posterior olecranon surface, plating displayed a significant reduction in gapping compared to the tension-band constructs $(0.532 \mathrm{~mm}(0.252-0.812)(\mathrm{p}=0.018))$. No cohort in any study displayed maximum gapping of $>2 \mathrm{~mm}$ during cyclic loading, regardless of the measurement location.

\section{DISCUSSION}

The thirteen high quality biomechanical studies included in this review determined the stability of olecranon constructs in response to cyclic loading through the extensor mechanism. Although plating displayed increased stability when looking at overall displacement (along with screw constructs which approached significance), new findings emerge when evaluating the data based on displacement location. As would be expected on the tension side of the fracture, the displacement measured near the posterior olecranon cortex was significantly higher than that of the articular surface for all constructs. There was no difference appreciated between TBW, intramedullary screw or plate fixation when looking at articular sided gapping. However, when measuring displacement at the posterior cortex, our data displayed a significant increase in stability when using plate constructs. Our study supports the principle that plating, which relies on static rigidity along the dorsal surface, allows for less distraction at this posterior location. This is in contrast to tension banding, which relies on converting posterior distraction forces to articular compressive forces. ${ }^{31}$

Many studies have performed biomechanical testing of olecranon fracture fixation. To our knowledge, this is the first to perform a systematic review of the available literature related to the subject. Our study supports the findings of Carofino et al, who observed no difference in biomechanical strength between tension band wiring and intramedullary screw fixation at either the articular or posterior surface. ${ }^{15}$ Hutchinson et al discovered that a screw with adjunctive tension banding decreased posterior surface fracture gapping when compared to intramedullary TBW, transcortical TBW, or an intramedullary screw alone. ${ }^{7}$ However, similar to our findings, they noted no difference between the four constructs when measuring displacement at the articular surface.

There is a paucity of studies comparing TBW and locked plating. Midtgaard et al discovered no difference in displacement during cyclic loading or load to failure when comparing tension band wiring to locked plating for transverse olecranon fractures. ${ }^{17}$ The authors Hahn et al showed no difference between TBW, intramedullary screws, and locking plates when evaluating compression at the fracture site, however, during a catastrophic failure test-defined as either implant breakage or $5 \mathrm{~mm}$ displacement- $100 \%$ of the TBW group failed compared to $0 \%$ in the screw or plate groups. ${ }^{32}$

Our paper reinforces the findings of Hutchinson et al and Sadri et al, showing there is no increased stability in tension band wiring when placing the K-wires through the anterior cortex versus down the intramedullary canal. ${ }^{7,22}$ Of note, none of the included studies evaluated K-wire prominence or back out. Although we found no benefit in regard to fracture site stability, some still advocate for this technique for the purpose of preventing posterior pin migration.

Several studies have tested the biomechanics of locked versus non-locked plating for olecranon fractures. Buijze et al showed no difference in load to failure or stiffness between precontoured locking plates and one-third tubular plates, even in comminuted fractures. ${ }^{33}$ Unfortunately, we were unable to perform a meaningful comparison in our study due to significant differences in measurement location between the two groups, as the non-locked cohorts were primarily articular measuring while the locked plates measured posteriorly. Plating is still the gold standard for comminuted olecranon fractures with no cortical contact, as both TBW and intramedullary screws rely on compression at the fracture site.

There are several limitations present in the current review. First, our systematic review included studies with significant heterogeneity. Initial literature review of olecranon fixation papers revealed substantial variation in study design and outcome measures. We attempted to limit this by focusing on studies that measured maximum displacement at the fracture site in response to cyclic loading simulating daily physiologic stresses. It is our contention that these studies better replicate the standard post-operative course after fixation. Despite all included studies attempting to simulate high intensity activities through loading of the elbow, there were still variations in regard to the testing set-up, quantity of force, and frequency of loading cycles. Second, although we wished to compare the effect of different techniques within each fixation type (IM screw with or without adjunctive tension banding, $7.3 \mathrm{~mm}$ versus $6.5 \mathrm{~mm}$ IM screws, etc.), many of these subgroups had too few of cohorts to make any meaningful comparison. Despite evaluating thirteen high quality studies, we would need a much larger sample to properly compare these different fixation configurations and techniques. Third, all of the included studies were cadaveric and involved stripping of surrounding soft tissue excluding the triceps muscle. This may lead to inaccurate representation of all the acting forces and soft tissue restraints around the human elbow. Lastly, our results can only be interpreted as accurate at time zero, as healing at the fracture site would likely change its stability. 


\section{CONCLUSION}

This systematic review of thirteen high quality biomechanical studies showed that there was no significant difference between tension band wiring, intramedullary screw, and plate constructs in their ability to maintain fracture reduction at the articular surface during simulated physiologic loading. Although plating displayed increased stability along the posterior cortex, it is our contention that maintenance of articular reduction is most important in these fractures. As no construct allowed gapping of over $2 \mathrm{~mm}$ at any location, all of the described fixation methods appear to be viable options for early postoperative motion. In addition, immediate active mobilization with limited resistance would put considerably less force on the olecranon compared to the simulated chair lift off or push up testing that these studies employed. Our study supports the idea that early postoperative motion is likely safe with any of these constructs.

Funding: No funding sources Conflict of interest: None declared

Ethical approval: Not required

\section{REFERENCES}

1. Rouleau DM, Sandman E, van Riet R, Galatz LM. Management of fractures of the proximal ulna. J Am Acad Orthop Surg. 2013;21(3):149-60.

2. Ring D, Jupiter JB, Gulotta L. Atrophic nonunions of the proximal ulna. Clin Orthop Relat Res. 2003;(409):268-74.

3. Weber BG, Vasey H. Osteosynthesis in olecranon fractures. Z Unfallmed Berufskr. 1963;56:90-6.

4. Chalidis BE, Sachinis NC, Samoladas EP, Dimitriou CG, Pournaras JD. Is tension band wiring technique the "gold standard" for the treatment of olecranon fractures? A long term functional outcome study. J Orthop Surg Res. 2008;3:9.

5. Rowland SA, Burkhart SS. Tension band wiring of olecranon fractures. A modification of the $\mathrm{AO}$ technique. Clin Orthop Relat Res. 1992;(277):23842.

6. Fyfe IS, Mossad MM, Holdsworth BJ. Methods of fixation of olecranon fractures. An experimental mechanical study. J Bone Joint Surg Br. 1985;67(3):367-72.

7. Hutchinson DT, Horwitz DS, Ha G, Thomas CW, Bachus KN. Cyclic loading of olecranon fracture fixation constructs. J Bone Joint Surg Am. 2003;85(5):831-7.

8. Nowak TE, Burkhart KJ, Mueller LP, Mattyasovszky SG, Andres T, Sternstein W, Rommens PM. New intramedullary locking nail for olecranon fracture fixation--an in vitro biomechanical comparison with tension band wiring. J Trauma. 2010;69(5):E56-61.

9. Gill JR, Vermuyten L, Schenk SA, Ong JCY, Schenk W. Olecranon fixation with two bicortical screws. Bone Jt Open. 2020;2;1(7):376-82.
10. Kia C, Dukas AG, Marshall ST. Biomechanical Comparison of Olecranon Sled Versus Intramedullary Screw Tension Banding for Olecranon Osteotomies. Orthop J Sports Med. 2018;6(12):2325967118816075.

11. Koziarz A, Woolnough T, Oitment C, Nath S, Johal $H$. Surgical Management for Olecranon Fractures in Adults: A Systematic Review and Meta-analysis. Orthopedics. 2019;42(2):75-82.

12. Meldrum A, Kwong C, Archibold K, Cinats D, Schneider P. Olecranon Osteotomy Implant Removal Rates and Associated Complications. J Orthop Trauma. 2021;35(5):265-70.

13. Fusaro I, Orsini S, Stignani Kantar S, et al. Elbow rehabilitation in traumatic pathology. Musculoskelet Surg. 2014;98:95-102.

14. Prayson MJ, Williams JL, Marshall MP, Scilaris TA, Lingenfelter EJ. Biomechanical comparison of fixation methods in transverse olecranon fractures: a cadaveric study. J Orthop Trauma. 1997;11(8):56572.

15. Carofino BC, Santangelo SA, Kabadi M, Mazzocca $\mathrm{AD}$, Browner BD. Olecranon fractures repaired with FiberWire or metal wire tension banding: a biomechanical comparison. Arthroscopy. 2007;23(9):964-70.

16. Lalliss SJ, Branstetter JG. The use of three types of suture and stainless steel wire tension banding for the fixation of simulated olecranon fractures: a comparison study in cadaver elbows. J Bone Joint Surg Br. 2010;92(2):315-9.

17. Midtgaard KS, Søreide E, Brattgjerd JE, Moatshe G, Madsen JE, Flugsrud GB. Biomechanical comparison of tension band wiring and plate fixation with locking screws in transverse olecranon fractures. J Shoulder Elbow Surg. 2020;29(6):12428.

18. Gruszka D, Arand C, Nowak T, Dietz SO, Wagner D, Rommens P. Olecranon tension plating or olecranon tension band wiring? A comparative biomechanical study. Int Orthop. 2015;39(5):955-60.

19. Gruszka D, Arand C, Greenfield J. Is the novel olecranon tension plate a valid alternative to tension band wiring of olecranon fractures? A biomechanical study on cadaver bones. Arch Orthop Trauma Surg. 2017;137(12):1651-8.

20. Petraco DM, Koval KJ, Kummer FJ, Zuckerman JD. Fixation stability of olecranon osteotomies. Clin Orthop Relat Res. 1996;(333):181-5.

21. Lalonde JA Jr, Rabalais RD, Mansour A. New tension band material for fixation of transverse olecranon fractures: a biomechanical study. Orthopedics. 2005;28(10):1191-4.

22. Sadri H, Stern R, Singh M, Linke B, Hoffmeyer P, Schwieger K. Transverse fractures of the olecranon: a biomechanical comparison of three fixation techniques. Arch Orthop Trauma Surg. 2011;131(1):131-8.

23. Hammond J, Ruland R, Hogan C, Rose D, Belkoff S. Biomechanical analysis of a transverse olecranon 
fracture model using tension band wiring. J Hand Surg Am. 2012;37(12):2506-11.

24. Boden AL, Daly CA, Dalwadi PP. Biomechanical Evaluation of Standard Versus Extended Proximal Fixation Olecranon Plates for Fixation of Olecranon Fractures. Hand (N Y). 2019;14(4):554-9.

25. Hackl M, Mayer K, Weber M. Plate Osteosynthesis of Proximal Ulna Fractures-A Biomechanical Micromotion Analysis. J Hand Surg Am. 2017;42(10):834.e1-834.e7.

26. Wallace BC, Small K, Brodley CE. Deploying an interactive machine learning system in an evidencebased practice center: abstrackr. In: Proceedings of the ACM International Health Informatics Symposium (IHI). New York: Association for Computing Machinery. 2012;819-24.

27. Nowak TE, Mueller LP, Burkhart KJ, Sternstein W, Reuter M, Rommens PM. Dynamic biomechanical analysis of different olecranon fracture fixation devices--tension band wiring versus two intramedullary nail systems: an in-vitro cadaveric study. Clin Biomech (Bristol, Avon). 2007;22(6):658-64.

28. Nowak TE, Mueller LP, Sternstein W. Dynamische Analyse von Osteosynthesen am Olecranon: ein invitro Vergleich zweier Osteosynthesesysteme [Dynamic analysis of olecranon osteosyntheses--an in vitro comparison of two osteosynthesis systems]. Biomed Tech (Berl). 2008;53(2):86-90.
29. Nowak TE, Burkhart KJ, Andres T. Locking-plate osteosynthesis versus intramedullary nailing for fixation of olecranon fractures: a biomechanical study. Int Orthop. 2013;37(5):899-903.

30. Wilke J, Krause F, Niederer D. Appraising the methodological quality of cadaveric studies: validation of the QUACS scale. J Anat. 2015;226(5):440-6.

31. Heim U, Pfeiffer KM. Internal fixation of small fractures: technique recommended by the AO-ASIF Group. 3rd ed. New York, NY: Springer. 1988;112.

32. Hahn A, O'Hara NN, Koh K, Zhang LQ, O'Toole RV, Andrew Eglseder W. Is intramedullary screw fixation biomechanically superior to locking plate fixation and/or tension band wiring in transverse olecranon fractures? A cadaveric biomechanical comparison study. Injury. 2020;51(4):850-5.

33. Buijze GA, Blankevoort L, Tuijthof GJ, Sierevelt IN, Kloen P. Biomechanical evaluation of fixation of comminuted olecranon fractures: one-third tubular versus locking compression plating. Arch Orthop Trauma Surg. 2010;130(4):459-64.

Cite this article as: Cutter B, Kelly SR, Beckett CR, Huish EG. The biomechanical strength of olecranon fixation constructs.Int J Res Orthop 2022;8:240-5. 